MARIA HELENA FERREIRA BRAGA BARBOSA

DEPARTAMENTO DE COMUNICAÇÃO E ARTE

UNIVERSIDADE DE AVEIRO

AVEIRO, PORTUGAL

ID+ UNIDADE DE INVESTIGAÇÃO EM DESIGN,

MEDIA E CULTURA

HELENAB@UA.PT
Fecha de recepción: 24/06/2017

Fecha de aceptación: 20/10/2017

Cómo citar: Barbosa, M. H. F. B. (2017).

Una historia de diseño del cartel en Portugal

del siglo XVII al XIX.

DOI: 10.5354/0718-2430.2016.44192

\section{Una historia de diseño del cartel en Portugal del siglo XVII al XIX}

\author{
A design history of the poster in Portugal from 17th to 19th century
}

Resumen. Contar una historia del diseño del cartel durante tres siglos en Portugal permite entender cómo ha cambiado este artefacto durante el tiempo. Generalmente, el resultado no configura los motivos que lo originaran, ya que no siempre son visibles y por lo tanto no ilustran la realidad en la que fueron diseñados.

Este artículo revela una serie de factores asociados no solo con los acontecimientos históricos, así como las limitaciones asociadas a la realización de un cartel. Para explicar esta narrativa la metodología adoptada referirá la tecnología (papel, producción y selección, técnicas de impresión, el uso de diferentes materiales), programa (categorías de cartel -políticos, culturales y comerciales- en paralelo con los acontecimientos históricos) y autoría (carteles anónimos e identificados, estilos y referencias). El artículo se divide en tres secciones, dedicadas a cada siglo tratado. El conjunto de ejemplos recogidos contribuye al conocimiento de la historia del diseño del cartel en Portugal.

Palabras clave: afiche político, Portugal, siglo XVII, siglo XVIII, siglo XIX.

\begin{abstract}
To write an history of the design of the poster about three centuries in Portugal allows to understand how this artefact has changed over time. Usually, the result does not configure the reasons that gave rise of the poster, because they are not always visible and so, they don't illustrate the reality in which they emerged.

This article reveals a series of factors associated not only with the historical events, as well the adjacent constraints to design a poster. Portugal has in some cases a particular path with regard to the design history of the poster. To reveal this history the adopted methodology to explain this narrative will refer the technology (paper production and selection, printing techniques, use of different materials), programme (categories of posters - political, cultural and commercial - in parallel with the historical events) and authorship (anonymous and identified posters, styles and references). The article is divided in four sections, where each section is related to one century. The set of examples collected contribute to the knowledge of the history of design of the poster in Portugal.
\end{abstract}

Keywords: political poster, Portugal, 17th century, 18th century, 19th century 
Figura 1. (1401-1433). Livro de horas del Rey

D. Duarte. Manuscrito iluminado. Fuente: Archivo Nacional de la Torre de Tombo, Lisboa, Portugal. Libro de las Leyes y Decretos. 1535.

(colección del autor).

1. Todos los carteles presentados en este trabajo fueron estudiados en el archivo de la Biblioteca Nacional de Portugal (BNP) que cuenta con 18.961 carteles catalogados. Para los siglos en estudio el total era de 196 carteles. Se procedió a la digitalización de todos los carteles para proceder a su análisis.

2. La dimensión comunicativa, cultural y su contexto histórico, las tecnologías utilizadas, las tipologías de los carteles (político, cultural y comercial) (Enel, 1974) (Moles, 2005), y de subcategorías, identificación de los artistas, incluyendo situaciones conectadas con la práctica del diseño.

3. Tres carteles políticos del siglo XVII, dos carteles políticos del siglo XVIII y 143 del siglo XIX: 38 políticos, 38 culturales y 67 comerciales.

4. Metodología presentada por Francisco Providência (2003).
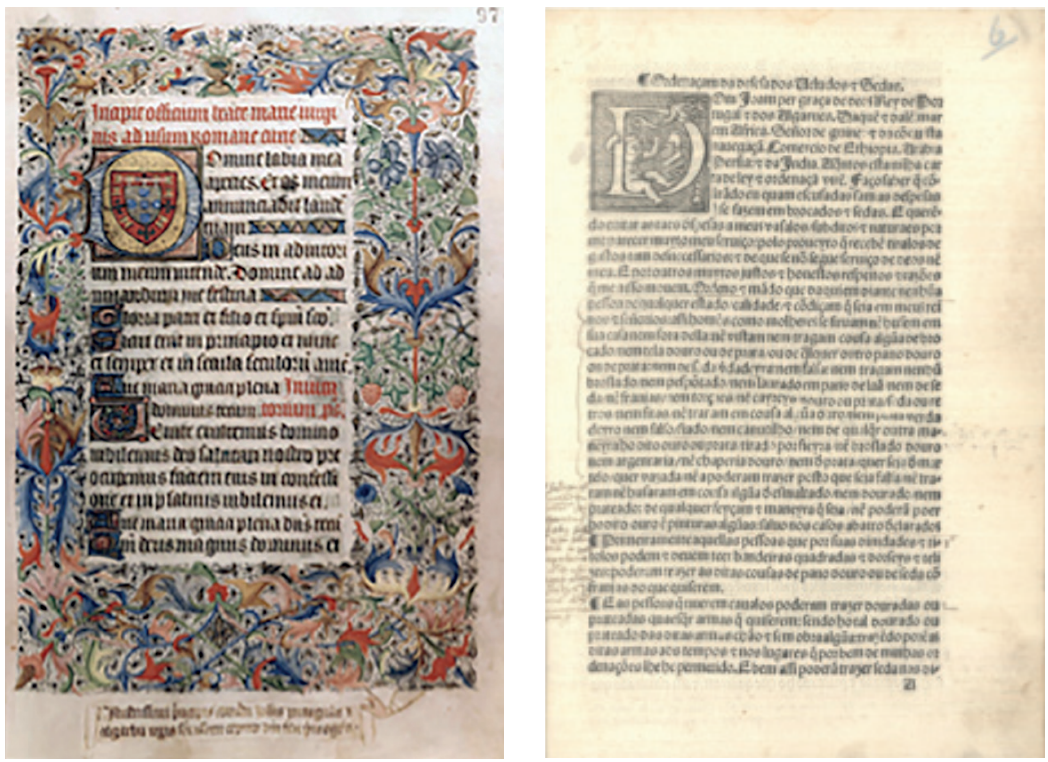

\section{Introducción}

Las publicaciones referidas a la historia del cartel en Portugal se centran generalmente en artistas y diseñadores abarcando temas y períodos a menudo circunscritos a un estilo o movimiento artístico. En este caso se reunieron asuntos integrales, desde el punto de vista diacrónico y sincrónico, tomando como base para el análisis y comprensión la utilización del diseño como recurso para la construcción de una narrativa. Así, el artículo presenta un enfoque amplio con el fin de contextualizar los temas considerados fundamentales para la comprensión de la historia del diseño del cartel portugués. Para construir este relato se ha recurrido primeramente al archivo más grande existente en Portugal. ${ }^{1}$ Más tarde, se ha hecho una selección basada en un conjunto de criterios ${ }^{2}$ que ha dado por resultado una muestra final de 143 carteles (de los cuales 12 aparecen en este artículo). ${ }^{3}$ Para una mejor comprensión y análisis de estos materiales en su contexto metodológico se ha creado una base de datos digital ${ }^{4}$. Paralelamente, se ha creado un mapa para la visualización previa del conjunto, con el objetivo de facilitar la comprensión de este objeto.

\section{El siglo XVII y el diseño del cartel: el legado del manuscrito iluminado} En términos de lenguaje gráfico, las órdenes religiosas acercaron la disposición del cartel a los manuscritos iluminados que se usaban en la época medieval y luego con los libros, caracterizados por llevar el texto en columnas. Los manuscritos iluminados fueron escritos principalmente en una o dos columnas de texto (Figura 1 ).

En los tres carteles del siglo XVII analizados es posible identificar un conjunto de influencias en relación con los manuscritos iluminados. El resultado de esta presentación visual estuvo condicionado por las tecnologías y materiales de impresión utilizados en este proceso: papel, matrices, máquinas de impresión. Aunque el primer registro para producir el papel nacional data del año 1411, solamente con la aparición de varias fábricas la industria del papel alcanza lentos progresos (Melo, 1926, pp. 25-26).

En el siglo XVII se encontró solo un registro, en 1663 , una licencia asignada a 


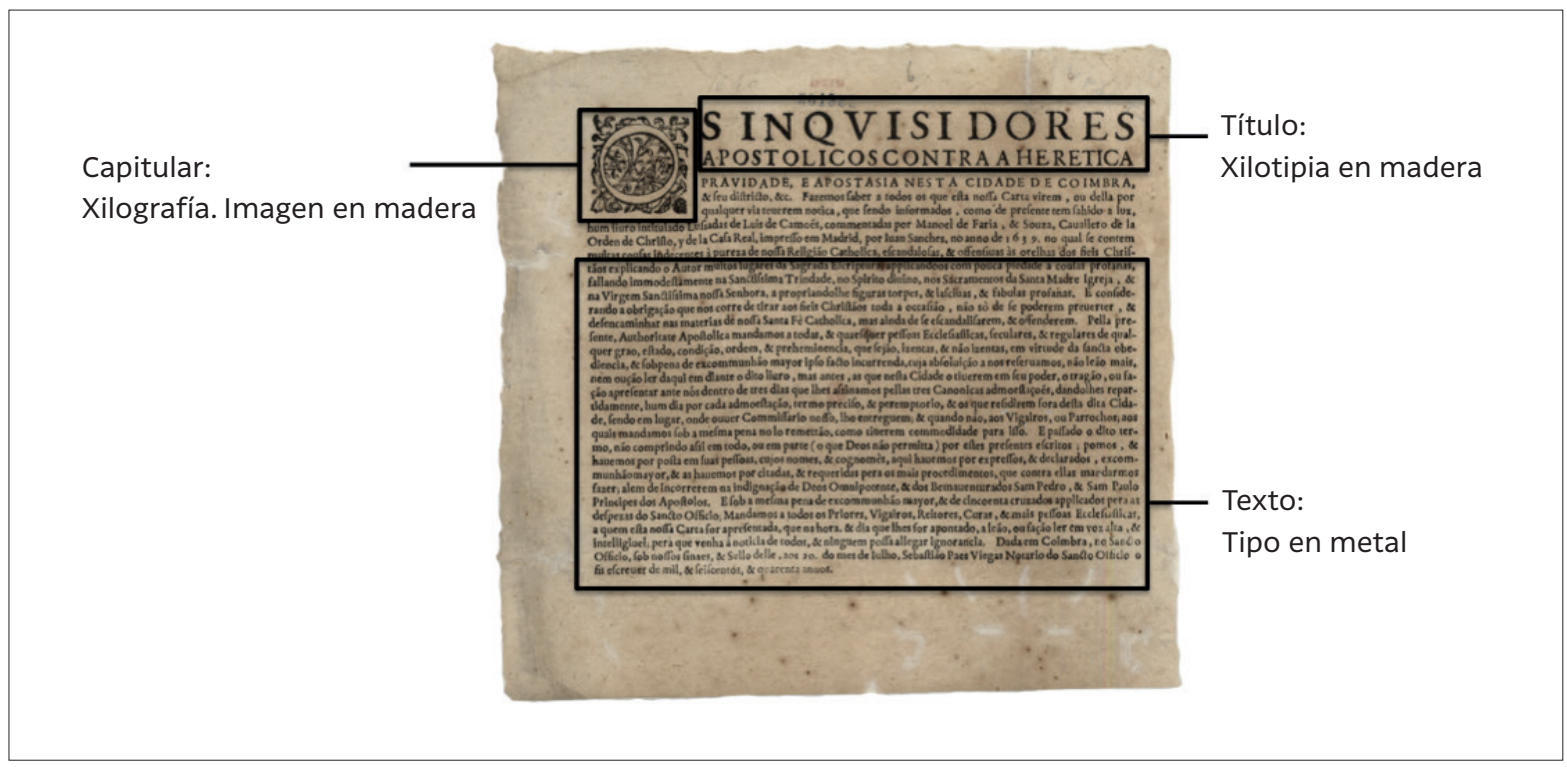

Pedro Dufour, que le permitió obtener papel y herramientas de corte en su taller (Melo, 1926, p. 27). El papel utilizado para imprimir carteles durante ese período puede ser de origen extranjero (Anselmo, 1983, p. 447). El tamaño de los moldes existentes hace suponer que el papel se utilizaba en su tamaño completo o estaba sujeto a corte, pudiéndose verificar en sus extremidades características relativas al acabado. La fuerte presencia de papel internacional en el contexto portugués, contribuyó a la existencia de marcas de agua. El tamaño de los marcos usados por el fabricante determinó las dimensiones de los pliegos y el diseño de la marca de agua se hizo a criterio de los productores.

En relación con la impresión, los elementos que caracterizan la reproducción de carteles de esta época son las capitulares -que se encuentran en xilografía-, el título se hacía generalmente en madera y el cuerpo de texto en tipos de metal (Figura 2).

Aunque José Martins señaló que “los caracteres móviles existían en Portugal probablemente desde el 1470-1480" (1997, p. 235), para hacer la identificación de los tipos utilizados en los títulos de carteles se examinó el archivo de la Universidad de Coimbra. Varias matrices móviles fueron encontradas posiblemente pertenecientes a partir de este período, sostenido en xilotipia con tamaños de entre 33 y 54 puntos, cuyo diseño se acerca al tipo utilizado en los carteles los siglos siguientes. Las máquinas de impresión y la prensa permanecieron en desarrollo continuo desde el siglo XVl; sin embargo, a pesar de esto, los carteles del siglo XVII presentan algunos defectos derivados de la falta de presión y también por el uso excesivo de los materiales. En ese siglo se encontraron solo dos talleres de impresión, uno ubicado en Coimbra y otro en Lisboa. Sin embargo, no fue posible identificar el nombre de las imprentas.

Los carteles del siglo XVII fueron medios de difusión elegidos para advertir al público de las iniciativas de censura tomadas por el Santo Oficio -la Inquisición- sobre libros o reproducciones impresas consideradas profanas. Las puertas y el interior de las iglesias eran los lugares habituales para poner car-
Figura 2. Cartel Anónimo. 1640; 28,3 × 27,5 cm. Archivo: Biblioteca Nacional de Portugal. 


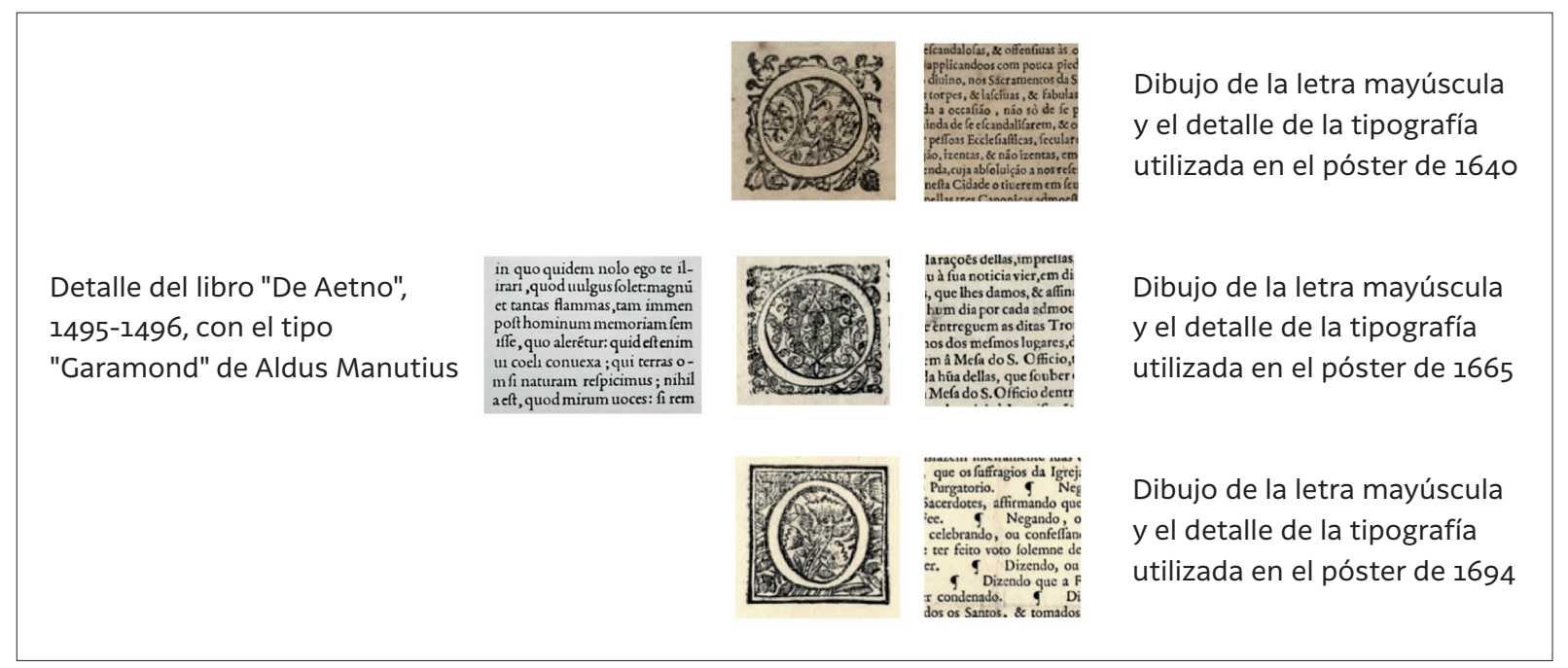

Figura 3. Comparación de los tipos y mayúsculas de los carteles de 1640, 1665 y 1694. Archivo: Biblioteca Nacional de Portugal.

5. Según el texto del cartel de 1655. teles y los responsables de colocarlos eran los sacerdotes, priores, prelados y vicarios de los conventos. ${ }^{5}$ Pero independientemente de su utilización, surge la siguiente pregunta: ¿Cómo se realizó el diseño del cartel en este período? Teniendo en cuenta que el cartel fue hecho por alguien en los talleres de impresión y dadas sus características, la colocación directa de las capitulares y caracteres móviles, no parece que haya habido ningún dibujo previo que se mostrara al cliente. En ausencia de estos dibujos, no es fácil referirse a los materiales involucrados en su implementación. Parece ser que a partir del programa proporcionado por el mandante su implementación daría directamente en lo que sería designado como prueba. Se desconoce si hubo un procedimiento entre el pedido y la producción, pues no existen documentos que revelen las negociaciones entre los impresores y los clientes. Asumimos entonces que los carteles pasaron directamente al proceso de reproducción. En cuanto a la tipografía, aunque no es posible identificar el nombre del tipo utilizado en los carteles, el diseño se aproxima a la tipografía creada por el renacentista italiano Aldus Manutius, Ilamado Garamond (1495), o con un tipo creado por Christophe Plantin (c. 1520-1589). Ambos tipos se caracterizan por el uso de largo ascendente y descendente. El uso de las ornamentaciones revela influencias de los períodos Barroco y renacentista. Los dibujos solo se centran en los motivos como plantas (tallos, hojas) y flores, cuya estructura de dibujo y composición tienen sus diferencias. Las letras mayúsculas, todas son blancas y su diseño tipográfico presenta también algunas diferencias (Figura 3).

\section{El siglo XVIII y el diseño del cartel: del manuscrito iluminado a la paginación}

No hay cambios sustanciales desde el siglo anterior, pero los cambios sutiles son reveladores. Los tipógrafos mantuvieron su actividad como en el siglo anterior. Principalmente hubo una mejora de las tipografías, que valoraban la calidad de la presentación de los carteles. En este período el Rey D. João V se abstuvo de comprar tipografías extranjeras, alentando los tipos de fundición realizados en el territorio nacional, promoviendo así la economía vernácula. En los dos únicos ejemplos de carteles encontrados en este siglo, se puede verificar algunos cambios en el cartel de 1791. Se conoce la figura del revisor, lo que implica la existencia de una prueba, pero este hombre trabajó solo 

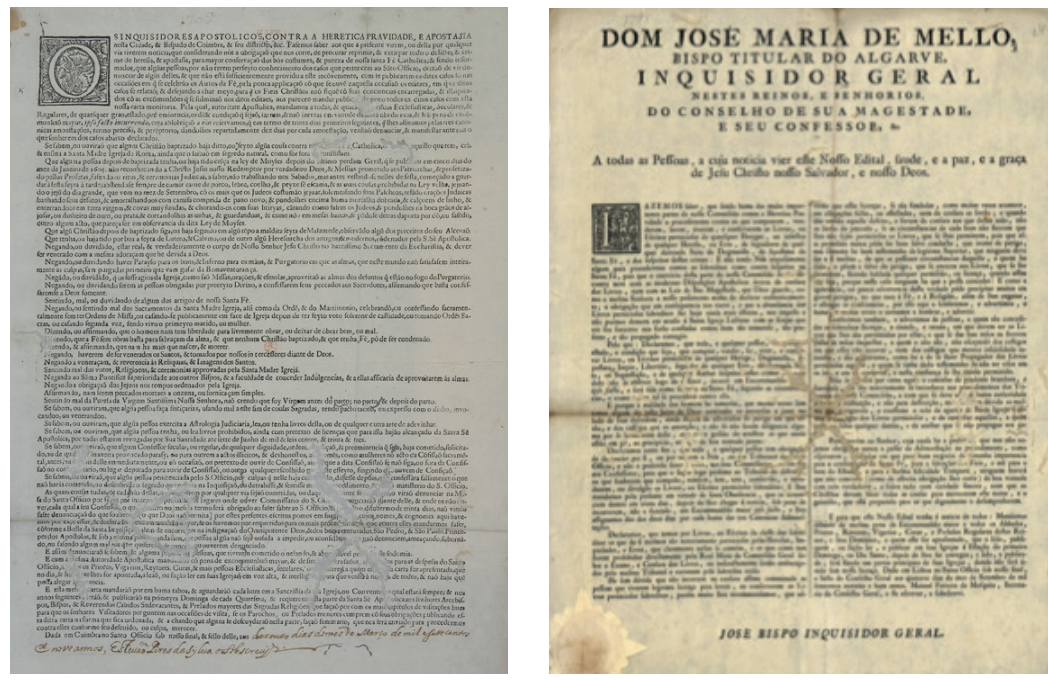

como corrector de textos y para certificar la inexistencia de errores ortográficos. Durante este período, se sabe que la prensa de la Universidad de Coimbra ha aumentado el número de tipos de metal, madera y grabar en madera, como resultado de la extinción de algunas imprentas (Figura 4).

La industria papelera portuguesa avanza en este siglo con varias fábricas especializadas en la fabricación de diferentes tipos de papel (Sequeira, 1935, [s.p.]). El papel utilizado en los carteles del siglo XVIII siguió presentando las características artesanales del siglo anterior, en términos de dimensiones, textura, color y formato. En relación a las máquinas de impresión hubo mejoras de las prensas de madera, que prolongaron su uso hasta el siglo XVIII, donde se promovió una mayor presión para conseguir mejor calidad.

Los lugares de impresión siguen siendo los mismos del siglo anterior: Lisboa y Coimbra. Pero, ¿cómo y dónde estaban los carteles visibles para el público? Según la publicación de Raphael Bluteau, (1712) desde principios del siglo XVIII existieron leyes que determinaban días específicos para colocar carteles en espacios públicos: "La ley establece el día en que traerán carteles para publicar los bienes que son para Venta, así como el día de dicha venta" (1712, pp. 169-170). El cartel político que aparece en la pintura de William Hogarth en 1754 Colocación de votos fue afijado de la misma forma que los comerciales. Este cartel fue pintado probablemente con el óleo en lona, y demuestra como los carteles fueron presentados al público en ese siglo (Figura 5). La colocación se realizó en múltiples ubicaciones. Las paredes eran el lugar más común. Con el aumento sustancial del número de afiches, su publicación se hizo sistemática. Surgió una nueva ocupación profesional. Aunque no se han encontrado registros de imágenes que ilustren el contexto portugués, se cree que esta práctica existió de manera puntual. Además de la afijación, considerando que estaban acondicionados para ello, ¿cuáles eran las condiciones de la producción de carteles?

Gran parte de la producción de carteles fue realizada por personas que trabajaban diariamente en los talleres de impresión, aunque nunca tuvieron una formación específica. La producción industrial fue el resultado de la experiencia adquirida en el ambiente de trabajo, y no sabemos si hubo alguna tendencia a producir artefactos con dominio técnico y de diseño para garantizar su calidad. En este período, los autores eran considerados 'pintor'

Figura 4. Anónimo, 1709; $41 \times 31 \mathrm{~cm}$. Archivo: Biblioteca Nacional de Portugal. Anónimo, 1791; 52 × 38,5 cm. Archivo: Biblioteca Nacional de Portugal. 
Figura 5. Canvassing for Votes, The Humours of an Election series, William Hogarth, 1755. Fuente: Sir John Soane's Museum, London.

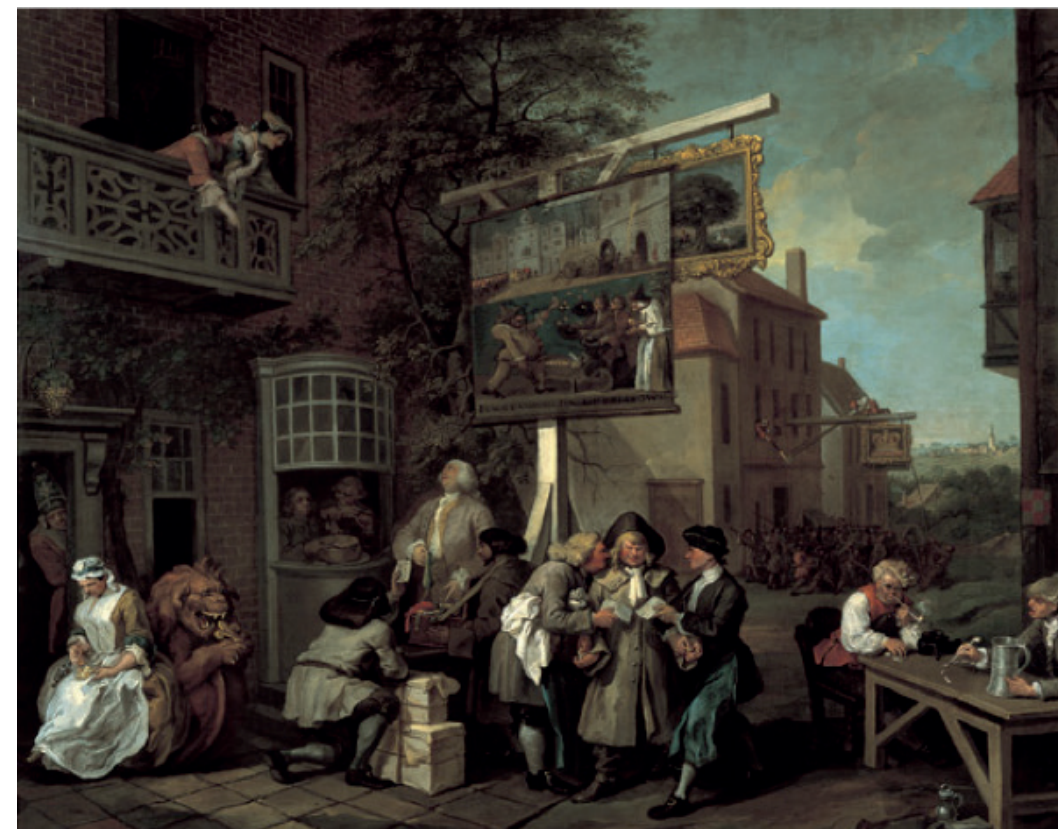

o 'artista'. Estos fueron los actores que se han distinguido por su calidad, porque estaban comprometidos en el arte de dibujar en un sentido artístico. Lamentablemente no se encontraron carteles en esa línea. Entonces, ¿cuáles fueron las influencias del programa y las soluciones presentadas por los tipógrafos? Los dos carteles del siglo XVIII, presentan algunas diferencias en su organización en la composición del cartel más que en relación a la cantidad del texto. Mientras que el cartel de 1709 revela las influencias del trazado de manuscritos ilustrados, reflejando el uso de la misma retórica visual detectada en el siglo anterior, el cartel de 1791 introduce una innovación que pretende crear una jerarquía de texto, mediante el uso de diferentes tamaños de tipos, dando lugar a espacios específicos en la composición del cartel. La parte superior del cartel presenta una organización tipográfica que se acerca a los frontispicios de las publicaciones, mientras que en la parte inferior es similar con la disposición del siglo anterior.

En cuanto a los tipos, los tipógrafos quedaron limitados por las opciones disponibles en el mercado. Aunque hay una ligera diferencia en el diseño del texto entre los carteles, se considera que las influencias tipográficas continúan siendo tributarias de Garamond, posiblemente porque los carteles eran considerados artefactos efímeros. Sin embargo, en el título del cartel de 1791 es posible verificar el uso de un diseño más reciente, con rasgos del período Clásico, que se desvían de la influencia renacentista habitual en el texto de los carteles. La variación de espesor entre tallos en la misma letra, con la variación entre los diferentes elementos que componen la letra, dibujando el contorno más recto, donde la letra parece ganar más austeridad, pasa por los avances tecnológicos en la realización de matrices y las herramientas utilizadas Para procesar en el diseño de tipografías, "[I]os refinamientos tecnológicos y las herramientas mejoradas caracterizan el desarrollo de nuevas tipografías en el período Clásico. [...] Las letras no eran diseñadas libremente, sino construidas con reglas, brújulas y cuadrículas" (Friedl, Otty Stein, 1998, p. 62). En consecuencia, es posible percibir tal cambio, donde el dibujo de las letras del 


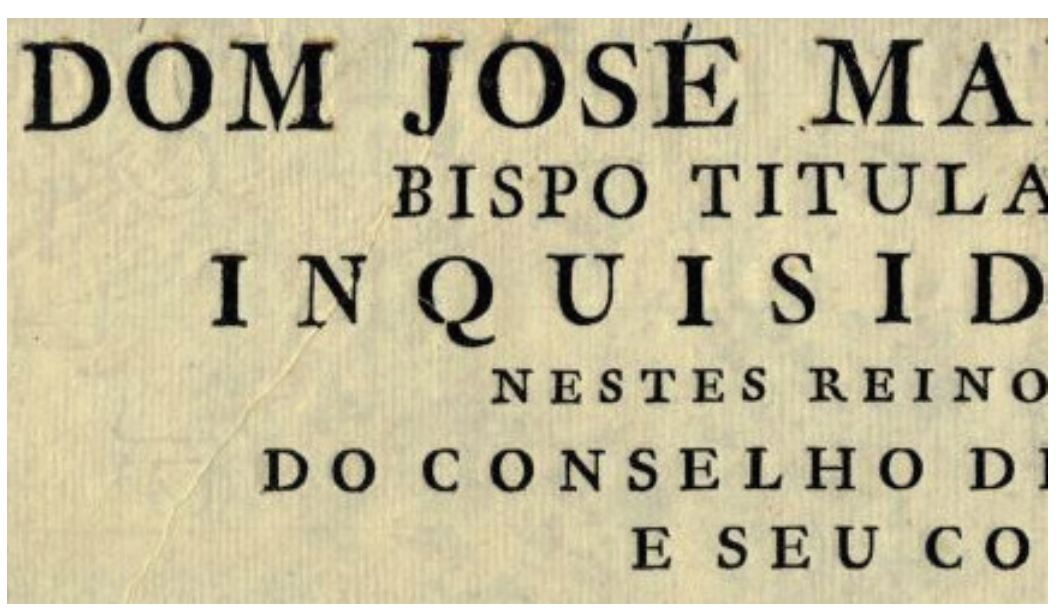

PRIMERA PARTE

DEL INGENIOSO HID A L GO

DON QUIXOTE

DE LA MANCHA.

\section{CAPÍTULO PRIMERO.}

Que trata de la condicion, y exercicio del famoso hidalgo Don Quixote de la Mancha.

título del cartel de 1791 se aproxima al tipo Ibarra creado en 1780, que se caracteriza por un dibujo más claro que define más precisamente la contra-forma de las letras (Figura 6).

En relación a la mayúscula ' $F$ ' de 1791 presenta un diseño más abstracto, con curvas, referida a la retórica visual utilizada en muebles, escultura y arquitectura bajo las volutas. Los motivos de la cáscara, la volumetría, los volúmenes que realzan el dinamismo y la exaltación de la forma son de estilo Barroco, presentando una solución menos figurativa que el cartel de 1709.

\section{El siglo xIX y el diseño del cartel:}

\section{el modelo de paginación y de los frontispicios}

Si en el siglo anterior los carteles reflejaban el modelo de paginación, en este siglo no solo persistía esta influencia, sino también de los frontispicios.

A nivel de la fabricación de papel, la tecnología en Portugal comenzó a popularizarse. El "papel-almaço" era un tipo de papel que se utilizaba en carteles de ese siglo. Es posible identificar dicha producción a través de la existencia de las marcas de agua. Sobre los ejemplos encontrados se verificó que los carteles usaban papel en gran mayoría venidos desde el extranjero, restringiéndose la producción nacional a un pequeño porcentaje. En este siglo, la producción artesanal pierde gradualmente terreno favoreciendo la industrial, donde el cartel de 1823, fue el primero que utilizó ese papel, marcando la transición entre la producción artesanal a la industrial. Durante el siglo XIX se
Figura 6. Detalle del título del cartel, 1791. Archivo: Biblioteca Nacional de Portugal. Dibujo del tipo "Ibarra" creado en 1780. Archivo: colección del autor. 


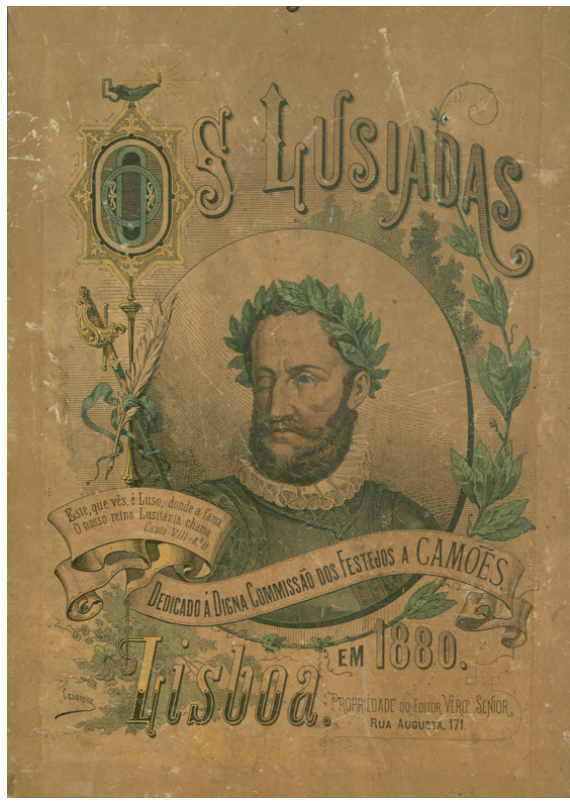

A N N U N C I O.

VEN DEM-SE OS B ILHETES D $A$

SUBSCRIPCุĂODOI.TOMO DASPOESIAS D E

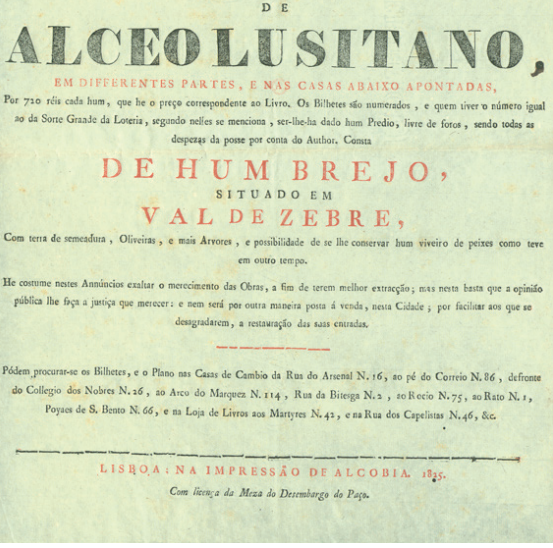

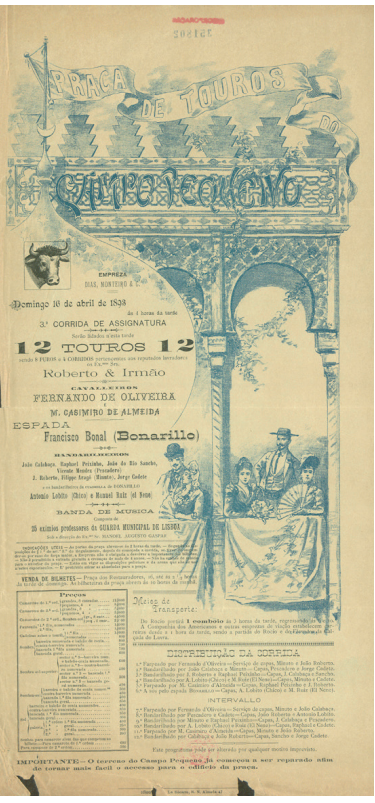

Figura 7. Casanova, 1880; 40,5 × 29 cm. Archivo: Biblioteca Nacional de Portugal.

Anónimo, 1825; 42,8 × 30,5 cm. Archivo: Biblioteca Nacional de Portugal.

Anónimo, 1893; 45 × 22,3 cm. Archivo: Biblioteca Nacional de Portugal.

6. Los ejemplos encontrados demostraron que los carteles que presentan estas características se imprimieron al nivel del texto en la Typ. La Bécarre, situada en Lisboa, y la imagen fue impresa en otros talleres que habían adquirido la tecnología litográfica. Esto reveló que los pedidos de los carteles posiblemente se realizaron a la Typ. La Bécarre, la que, al no poseer el sistema litográfico para la impresión de la imagen, recurría a otras casas de impresión que utilizaban la litografía,

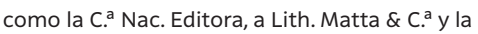
Lith. de Portugal, todas situadas en Lisboa.

7. El prelo construido por Manuel Bernardes Galinha en 1845, conocido como "Prelo do Galinha", fue designado con el nombre del artífice por ser conocido como "hábil cerrajero de Coimbra, que perteneció a una famosa dinastía de fabricantes de hierro forjado y fundido" cuyo sistema fue utilizado en la Imprensa da Universidade de Coimbra (IUC) (información cedida por e-mail de la directora adjunta de la IUC). encontraron 82 carteles impresos en papel artesanal y 71 carteles impresos en papel industrial.

El color en el papel también aparece en este siglo, y se encontraron ocho carteles en estas condiciones. Al nivel de las dimensiones se debe observar que la dimensión más pequeña era de $12,3 \mathrm{~cm}$ y la más grande era de $142 \mathrm{~cm}$.

En la reproducción de carteles apareció un nuevo material en los talleres de impresión, que revolucionó la apariencia visual: la litografía. Esto permitió la gran impresión. Esta técnica de impresión fue fundamental para trabajar especialmente la imagen, valorando por primera vez la importancia de dibujar sobre el cartel. En cuanto al proceso litográfico, a pesar de la existencia de un diseño anterior hecho en papel, las representaciones visuales posteriormente fueron a través de un papel translúcido, o directamente sobre la piedra, utilizando lápices, plumas, cepillos y tinta para dibujar. El ejemplo en este cartel muestra las diversas posibilidades de la litografía. A pesar de que la técnica fue inventada por Alois Senefelder (1771-1834) en 1796, fue introducida en Portugal recién el año 1824, en la Officina Regia Littográfica, de Lisboa (Costa, 1925, pp. 8-18). Uno de los primeros carteles que utiliza esta litografía es de 1880 y es también el primer cartel identificado con la firma del autor (Figura 7).

En ausencia de la imagen, los carteles impresos tipográficamente, buscaban atraer la atención del público utilizado la introducción del color rojo junto con el negro. Esto sucedió con el cartel de 1825. Los carteles de finales de siglo comenzaron a combinar diferentes tecnologías de impresión. Los carteles de tauromaquia son ejemplos que ilustran aquello. Algunos fueron impresos en talleres de impresión diferentes, combinando tipografía y litografía. ${ }^{6}$ También fue posible encontrar carteles impresos con otras tecnologías, como la cincografía y el fotograbado.

Además, la industria de máquinas ha ido mejorando la calidad de la impresión. Desde 1834, el número de las impresiones mecánicas ha aumentado considerablemente.7 Con la introducción del vapor en torno a 1860 (Rocha, 1998, p. 33), la reproducción de los objetos impresos, y por consiguiente de los carteles. En consecuencia, durante el siglo XIX se encontrarán en Portugal nuevas 

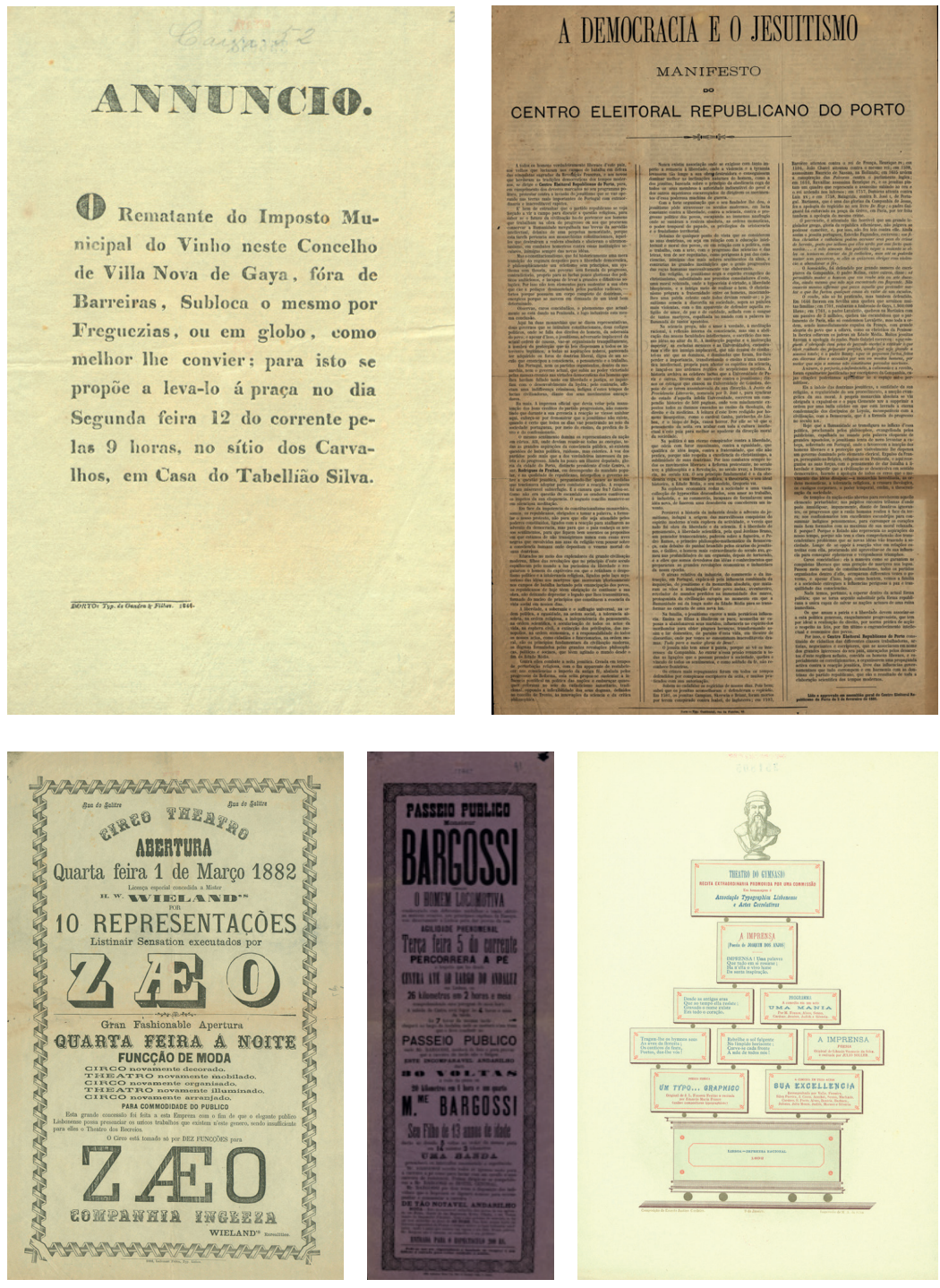

casas de impresión. ${ }^{8}$ En ese contexto, ¿cuál fue el resultado gráfico en términos de la comunicación visual propuesto por los tipógrafos?

Una mirada a las diferentes categorías de los carteles -política, cultural y comercial- ayuda a percibir las influencias del programa y la interpretación de la autoría. En este siglo solo se firmaron dos carteles. En general los carteles políticos tenían variaciones manteniendo constante el empleo de un escudo, o con una composición a una sola columna o bien de tres columnas que se acercaban a la disposición de una página de periódico (Figura 8).

En relación con el cartel cultural muestra una mayor diversidad en la composición y en la valorización de la imagen. La presencia del dibujo, la introducción del color representado en los contenidos, la selección de papel coloreado, el empleo de otras tecnologías de impresión que van más allá de la tipografía son argumentos que permiten afirmar que el cartel cultural presenta una mayor libertad de expresión, menos limitada por las condiciones impuestas por el programa (Figura 9). En los carteles comerciales los mensajes de texto, a pesar de seguir extensos, empiezan a ser más breves. El uso de imágenes, la colocación de márgenes y
Figura 8. Anónimo, 1810; $21 \times 31 \mathrm{~cm}$. Archivo: Biblioteca Nacional de Portugal.

Anónimo, 1846; 21,5 × 30,7 cm. Archivo: Biblioteca Nacional de Portugal.

Anónimo, 1881; 36 ×60cm.Archivo: Biblioteca Nacional de Portugal.

Figura 9. Anónimo, 1882; $45 \times 30 \mathrm{~cm}$. Archivo: Biblioteca Nacional de Portugal.

Anónimo, 1882; 59 × 20 cm.Archivo: Biblioteca Nacional de Portugal.

Ernesto Justino Cordeiro, 1892; 27,9 x 18,9 cm. Archivo: Biblioteca Nacional de Portugal.

8. En Portugal la valorización dada a la utilización de nuevas tecnologías era tan importante que el uso del nombre 'vapor' surgió en la identificación de algunas casas impresoras, como sucedió con la Typographia a Vapor de la Empreza Litteraria y Typographica, situada en la R. de D. Pedro, 184, en Porto, que imprimió el cartel político de 1897. Además, se verificó que la importancia dada a la energía a vapor, en el área de la impresión, acabó por fomentar toda la tecnología portuguesa. Un ejemplo es la Fábrica de Massarelos situada en Porto, que creó en 1882, un prelo mecánico que "no era inferior a sus congéneres extranjeros" (Cabral, 1997, p. 13). 


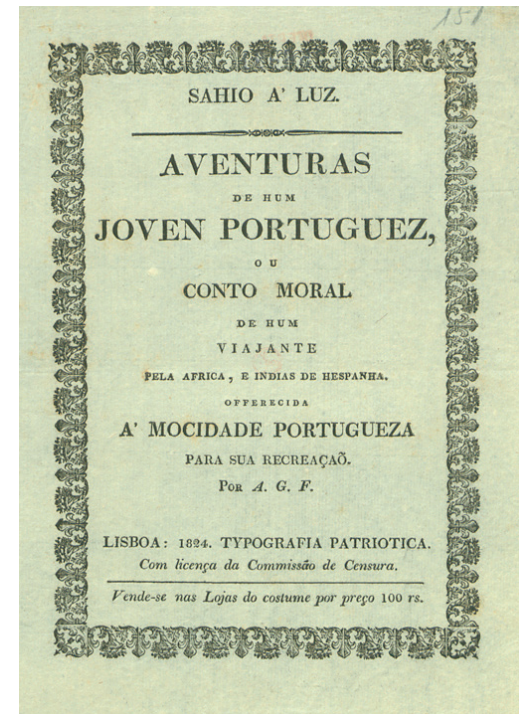

Figura 10. Anónimo, 1824; 21,3 × 14,9cm. Archivo: Biblioteca Nacional de Portugal.

Anónimo, 1825; $43 \times 32$ cm. Archivo: Biblioteca Nacional de Portugal.

Anónimo, 1889; 45 × 32 cm. Archivo: Biblioteca Nacional de Portugal. emblemas se convirtió en una presencia más constante en comparación con el cartel político (Figura 10).

\section{Conclusiones}

A pesar del rango cronológico en la producción de carteles analizado, se verificó que apenas en dos casos el diseñador se identifica, revelando que la participación de artistas en el escenario del cartel surge apenas al final del siglo XIX. Paralelamente, la litografía fue responsable de la presencia de la imagen de grandes dimensiones, atrayendo cada vez más a los artistas, y comienza a ser utilizada en los carteles culturales y comerciales. Desde el punto de vista del programa, los carteles políticos eran poco atractivos, mientras que los culturales y los comerciales lograron hacerse más apelativos al público. Se ha verificado que el concepto del cartel ha evolucionado con el tiempo, trazando la génesis de la comunicación y de su anunciación perenne. Concluyese que la evolución formal del cartel portugués es el espejo de la historia del diseño gráfico en el país, y el registro del diseño siempre se ha logrado mantener próximo a la producción visual de carteles realizados a nivel internacional.

\section{Referencias}

Anselmo, A. (1983). Les origines de l'imprimerie au Portugal. Etudes II. Braga, Portugal: Barbosa \& Xavier, Limitada Editores.

Bluteau, R. (1712). Vocabulario portuguez e latino. Vol. II. Coimbra, Portugal: Collegio das Artes da Companhia de Jesus, 1712.

Cabral, L (1997). Miniaturas de máquinas tipográficas: exposição. Porto, Portugal: Biblioteca Pública Municipal do Porto.

Costa, L. X. da (1925). A obra litográfica de Domingos António Sequeira: com um esboço histórico dos inícios da litografia em Portugal. Lisboa, Portugal: [s.n.].

Enel, F. (1974). El cartel: lenguaje, funciones, retórica. Valencia: Fernando Torres.

Friedl, F., Ott, N., y Stein, B. (1998). Typography: when who how, Typographie: wann wer wie, Typographie: quand qui comment. Köln: Alemanha: Könemann.

Martins, J. V. de P. (1997). O Humanismo (1487-1537). In História da Universidade em Portugal. Coimbra-Lisboa, Portugal: Universidade de Coimbra e Fundação Calouste Gulbenkian.

Melo, A. (1926). O papel como elemento de identificação. Lisboa, Portugal: Biblioteca Nacional.

Moles, A. (2005). O cartaz. São Paulo: Editora Perspectiva.

Providência, F. (2003). Algo más que una hélice. En A. Calvera (Ed.) - Artę? Diseño. Barcelona: Gustavo Gili, 2003. p. 195-213.

Rocha, J. L. de M. (1998). O essencial sobre a imprensa em Portugal. Lisboa, Portugal: Imprensa Nacional-Casa da Moeda.

Sequeira, G. (1935). A Abelheira e o fabrico do papel. Lisboa, Portugal: [s.n.]. 
